\title{
Hispanismes
}

Revue de la Société des Hispanistes Français

\section{Clarice Lispector e o conto moderno brasileiro}

Observações sobre "O búfalo", do livro Laços de família

Clarice Lispector y la nouvelle moderne brasilienne. Observations sur "O búfalo", de Laços de família

Clarice Lispector y el cuento moderno brasileño. Observaciones sobre "O búfalo", de Laços de família

Clarice Lispector and the Modern Brazilian Short Story. Observations about "O búfalo", of Laços de família

\section{Vilma Arêas}

\section{(2) OpenEdition}

\section{Journals}

\section{Edição electrónica}

URL: https://journals.openedition.org/hispanismes/672

DOI: 10.4000/hispanismes. 672

ISSN: 2270-0765

\section{Editora}

Société des Hispanistes Français

\section{Refêrencia eletrónica}

Vilma Arêas, «Clarice Lispector e o conto moderno brasileiro », HispanismeS [En ligne], 15 | 2020, mis en ligne le 01 juin 2020, consulté le 31 juillet 2021. URL : http://journals.openedition.org/hispanismes/ 672 ; DOI : https://doi.org/10.4000/hispanismes.672

Este documento foi criado de forma automática no dia 31 julho 2021.

\section{$(\mathbb{\theta} \Theta \Theta$}

Les contenus de cette revue sont mis à disposition selon les termes de la Licence Creative Commons Attribution - Pas d'Utilisation Commerciale - Pas de Modification 4.0 International. 


\title{
Clarice Lispector e o conto moderno brasileiro
}

\author{
Observações sobre "O búfalo", do livro Laços de família \\ Clarice Lispector y la nouvelle moderne brasilienne. Observations sur "O búfalo", \\ de Laços de família \\ Clarice Lispector y el cuento moderno brasileño. Observaciones sobre "O búfalo", \\ de Laços de família \\ Clarice Lispector and the Modern Brazilian Short Story. Observations about " 0 \\ búfalo", of Laços de família
}

\section{Vilma Arêas}

A única estrutura que admito é a óssea.

Clarice Lispector ${ }^{1}$

"O búfalo" é um dos textos menos analisados da obra de Clarice Lispector, e poderemos mais tarde levantar uma hipótese em relação a esse esquecimento. Trata-se de um conto incluído em Laços de familia ${ }^{2}$, coletânea que teve a sua origem em outro pequeno volume de seis contos, escrito oito anos antes ${ }^{3}$. No conjunto completo dos treze contos, "O búfalo" ocupa o último lugar, o que pode talvez acrescentar algum sentido extra à narrativa. A essa altura a escritora já havia escrito seus primeiros romances e confessou numa entrevista ter então desejado fazer uma nova experiência literária. Segundo ela, a "história curta" oferecia melhores condições para a manufatura do texto, podendo até mesmo chegar ao virtuosismo, "sem maior prejuízo do conteúdo"4.

O exame de "O búfalo" será baseado principalmente na leitura insistente do texto, sabendo que ler significa reler. Partirei de uma descrição do conto em seus traços básicos, acrescentando a análise dos dados, que completam, modificam ou dão o tom da narrativa, finalizando com sua interpretação. Esta necessariamente incluirá o lugar do conto no conjunto de Laços de familia, para que fique mais clara a particularidade de sua composição. Às vezes essas três etapas se misturam ou se ajustam, às vezes corrigem opções, mas estarão sempre presentes. Por exemplo, uma descrição sumária do conto dirá que ele decorre durante uma tarde na vida de uma mulher, que, ao ser abandonada 
pelo amante, vai ao Jardim Zoológico a fim de aprender a odiar com os animais. Mas lá só encontra amor. Após examinar várias jaulas e em seguida dar uma volta na montanha-russa, ela encontra um búfalo, e com ele troca imaginariamente a experiência desejada. Sente-se então inocentada do "mútuo assassinato" (p. 135), pensa no punhal que "ela mesma cravara" (p. 135), tem uma vertigem e desmaia.

o que acabamos de ler é o núcleo do enredo, mas temos que ampliá-lo para obtermos maior número de dados, exigidos para uma análise. Assim: numa tarde de primavera, uma mulher, da qual nem mesmo sabemos o nome, vai ao Jardim Zoológico, vestida com um casaco marrom. Esta informação, várias vezes repetida, transforma-se numa marca ou máscara da personagem. Ela não vai a passeio, o que seria comum. Em vez disso, acha que tem uma espécie de missão violenta a cumprir, uma "carnificina" (p. 126), ou um "massacre", palavras dela. Quer aprender com os animais enjaulados o sentimento de ódio, pois fora recusada por um homem. Afirma que a ela só ensinaram o perdão e "a amar, a amar, a amar" (p. 131). Nada nos é dito sobre o homem, nem são mencionados pormenores da relação que mantinham.

Dois cenários criam a atmosfera dos três segmentos da trama, desenhando a moldura da ação: o chão, onde decorrem o primeiro e o último segmento, em geral referidos ao presente, e os ares, no segmento intermediário, que nos oferece informações importantes do passado da personagem. Esta manobra nos permite observá-la de dois ângulos, no baixo e no alto, e em dois tempos, presente e passado. No primeiro segmento da trama, ela passeia entre as jaulas, observando os animais. Para sua surpresa, em vez do ódio que esperava encontrar, verifica que todos estão se amando, como o leão e a leoa, ou amamentam suas crias, como uma das macacas. Um macaco, que a encara "sem pestanejar" (p. 127), desperta nela a vontade de matar. Confessa que atiraria entre seus olhos. Mas de repente percebe que era um macaco velho e cego, "um véu branco gelatinoso cobria suas pupilas" (p. 127). A mulher foge, pois seu projeto era "somente odiar", não sentir piedade ${ }^{5}$, como o trecho leva a crer. Os outros animais também a desapontam, pois era primavera, estação das flores e dos amores, nenhum deles a ajudava a "encontrar-se com o próprio ódio" (p. 126). Concentra-se tanto nessa busca "que sua vista às vezes se escurecia num sono, e então ela se refazia como na frescura de uma cova" (p. 126).

Depois dessa estranha referência à morte ${ }^{6}$, passamos ao segundo segmento da trama, quando a mulher desiste da procura entre as jaulas e se afasta para dar uma volta na montanha-russa, no parque de diversões do Jardim Zoológico. Queria "sozinha ter a sua violência". Agora está longe dos animais e rodeada de jovens. Entra na fila dos namorados e vai se sentar sozinha num banco, no carro da montanha-russa. "E ali estava agora sentada, quieta no casaco marrom" (p. 128). Está separada dos outros, "parecia estar sentada numa Igreja" (p. 128-129). Quando olha para baixo vê entre os trilhos, no chão, a erva verde, que a faz lembrar-se outra vez do amor e não do ódio. Ela recusa a tentação de ceder, pois era "sempre tão mais fácil amar" (p. 129). De repente o movimento violento da montanha-russa a transforma numa boneca descontrolada, jogada de um lado para outro, de saia levantada, o que a faz lembrar-se de episódios constrangedores de seu passado. Uma frase, repetida logo a seguir, resume o mal-estar: "faziam dela o que queriam" (p. 129), o que significa uma "grande ofensa" (p. 129), ou seja, sua má reputação por não resistir ao sexo. Ela era "uma fêmea de presa" (p. 132), isto é, uma mulher destinada a ser caçada como um animal, palavras também ofensivas. (Não nos esqueçamos que este conto foi escrito na década de 1950, há mais de meio 
século, quando a desigualdade de gêneros e classes no Brasil, até hoje constrangedora, era indiscutível.) A mulher do casaco marrom também não conseguia resistir à "dançando descompassada ao vento" (p. 129), enquanto ouvia "o grito das namoradas" (p. 129). Tem uma sensação de "morte às gargalhadas" (p. 129), morte "sem aviso, de quem não rasgou antes os papéis da gaveta" (p. 129). É fácil concluir que ela se refere a ocorrências, talvez segredos, que deveriam ser guardados e não expostos.

6 No terceiro e último segmento, ela está de novo caminhando, depois de se sentir "jogada fora de uma Igreja" (p. 129), "fraca e difamada" (p. 130) como no dia em que sua bolsa caíra e seus pertences banais, "os andaimes de sua vida" (p. 130), ficaram expostos a todos, o que reforça a ideia de segredos revelados sugerida no parágrafo anterior. Caminhava agora como se tivesse sido atropelada, alisando a saia com recato. Numa inversão de sentidos, pois está rodeada pelas jaulas dos animais, ela própria é que se sente enjaulada, sinal de sua depressão. Encontra um quati (pequeno urso de focinho pontudo) que se assemelha a uma criança curiosa "lhe fazendo uma pergunta" (p. 130). Por fim vê em um grande terreno, cercado com grades altas, um búfalo, minuciosamente descrito: a cor negra, os cornos alvos, o torso, pescoço, ilhargas, movimentos. Há a descrição também minuciosa de um jogo imaginário de sedução entre ambos, à semelhança de uma dança erótica de aproximação e afastamento. Afinal o búfalo satisfaz o desejo da mulher, ou seja, sua "vontade atormentada de ódio" (p. 131). Isso é descrito como uma promessa ritual de "sagrado sangue e triunfo" (p. 131), e também "um tormento como de amor" (p. 131). As relações são explícitas e paradoxais, identificando o homem que a recusara com o búfalo: "Eu te amo, disse ela então com ódio para o homem cujo grande crime impunível era o de não a querer. Eu te odeio, disse implorando amor ao búfalo" (p. 134). Na tarde iluminada o búfalo "era um corpo enegrecido de tranquila raiva [...] A morte zumbia nos seus ouvidos" (p. 133). Ambos se olham profundamente. Ela dá "um suspiro de sono" (p. 135), sem querer ou poder fugir, "presa ao mútuo assassinato [...]" (p. 135), sente a mão grudada para sempre ao punhal, "que ela mesma cravara" (p. 135). Antes de cair numa lenta vertigem, ela vê "o céu inteiro e um búfalo" (p. 135).

7 A confissão clara e brutal de ter apunhalado alguém só acontece ao final, momento em que ela relaxa em paz, "De pé, em sono profundo" (p. 135) ("inocentada", "inocente" e "ingênua" são três adjetivos que a descrevem naquele momento). Então tomamos consciência de que a morte e o sentimento de culpa estão presentes desde o começo da narrativa, não apenas como uma suspeita, mas como uma luta que só pode terminar em seu auge, em "sagrado triunfo" (p. 131), numa lógica narrativa que vai sendo sempre atada e desatada. Assim, apesar da confissão, ainda nos perguntamos, misturando os níveis de compreensão do conto: será mesmo verdade? Ela merecerá crédito? O final dramático da perda de consciência também já vinha sendo trabalhado desde o segundo parágrafo do texto, na alusão à vista escurecida "num sono", simbolicamente irmão da morte, o que talvez arraste a estranha imagem da mulher a se refazer "como na frescura de uma cova" (p. 126). Essas expressões também se articulam ao final, quando ela ouve "pingar como numa grota aquele primeiro óleo amargo, a fêmea desprezada" (p. 134). Em momentos como esses, o conto usa das tintas da narrativa de mistério e horror, como esse "óleo amargo" pingando numa grota ou gruta, lugar pouco acolhedor, talvez perigoso, caverna etc. A mulher também chama a si própria de “assassina incógnita" (p. 131) e sua missão era "uma missão mortal" (p. 130). 
8 Apesar de tantas passagens que se remetem umas às outras ao redor da recusa amorosa, existem pontos duvidosos, não explicados suficientemente, talvez pela perturbação da protagonista, atormentada e presa de emoções extremadas e contraditórias ${ }^{7}$; talvez pela fusão do narrador (ou narradora) com sua personagem, à semelhança de outros contos da escritora ${ }^{8}$, principalmente em Laços de familia. Quem realmente fala em "O búfalo"? De saída, o conto começa com o "mas" adversativo, conjunção que significa oposição ou objeção ao que foi dito ou enunciado antes. Entretanto nada foi dito antes e batemos de frente com a objeção do "mas": "Mas era primavera" (p. 126). É esta ordem invertida que se propaga, o que também facilita o tom errante do texto, difícil de agarrar. Apesar da relação que as obras de arte mantêm com os jogos, suas máscaras e ilusões, o propósito da protagonista de iniciar uma busca ao ódio e a uma carnificina num Jardim Zoológico a princípio não convence, porque as contradições não nos preparam para a desavença brutal dos sentimentos. Isso é tão difícil de compreender que a própria mulher do casaco marrom imagina aprender a odiar com animais, embora odiar e amar estejam juntos. De qualquer modo, foi a rejeição do amante que instaurou o momento de crise, a ruptura com o sentimento amoroso, que estremece sempre ou desliza.

9 Por outro lado, e mudando de nível, não podemos também nos esquecer das palavras de Clarice em relação às plantas e animais espalhados por seus textos, entrevistas, cartas: "[...] um tomateiro é arte pela arte", ou "bicho, uma das formas acessíveis de gente"10. Esta ausência confessada de limites entre o mundo humano e os mundos vegetal e animal aparece frequentemente nos textos, que se alargam para acolher outros recursos na condução de um tema, a exemplo de associações livres, conscientes ou inconscientes.

10 "O búfalo" parece caber inteiramente nas palavras ditas por Clarice numa entrevista a Pedro Bloch ${ }^{11}$ : "Comecei a escrever, com sete anos, histórias que ninguém publicava [...]. Todas as histórias publicadas contavam fatos. As minhas relatavam repercussões de fatos". Realmente, a cada vez em "O búfalo" a mesma história é quebrada e recontada intermitentemente, em termos que "repercutem" de maneira ligeiramente modificada ou desfocada, como um debrum ao redor de outra coisa. "Repercutir" significa refletir, dar nova direção, fazer sentir indiretamente, e é isto o que acontece. Na entrevista que Clarice deu aos editores do Pasquim em junho de $1974^{12}$, eles começaram justamente falando sobre "O búfalo", com a seguinte afirmação de Ziraldo ${ }^{13}$ : "Ela narrava não o que estava acontecendo com o búfalo ou sobre a personagem, mas o que estava havendo no espaço entre os dois" . E: "[...] acho que você escreve muito mais sobre as possibilidades do que sobre o fato em si". A afirmativa pode ampliar sugestões. Por exemplo, se a protagonista vai ao Jardim Zoológico para encontrar o próprio ódio, logo em seguida é dito que ela queria encontrar "o ponto pior de sua doença" (p. 126), que fora ali "para adoecer" (p. 126). Todas essas palavras, "doença, doente, adoecer", têm parentesco com "dolor", dor. Ela fora ao Jardim Zoológico para adoecer de dor. Quer portanto, caminhar, em direção ao próprio sofrimento, como numa penitência, palavras importantes no texto, derivados do sentimento de culpa, mas lançando mão de uma prece religiosamente inadequada: "Deus, me ensine somente a odiar" (p. 127), o que pode significar uma resistência à educação religiosa que recebera, que apenas ensinava a perdoar, a resignar-se, a ter "a doçura da infelicidade" (p. 131). Ela quer mudar essa situação, mas como "cavar a terra até encontrar a água negra, como abrir passagem na terra dura e chegar jamais a si mesma?" (p. 127). 
11 Num outro momento, a própria mulher afirma que o único crime do homem "era o de não amá-la" (p. 127), o que era um crime “impunível”, isto é, sem punição legalmente possível. Ela quer dizer que a noção legal de crime não pertence ao sentimento ou às certezas subjetivas. Então tudo o que estava sendo discutido, algo como uma vingança e ameaça de morte, está em outro patamar. Trata-se então de outra coisa?

Mas essas questões, ligadas a crimes e castigos, estão também misturadas com a descrição dos animais, que se abre à fantasia, fazendo os leitores entrarem no reino do maravilhoso. Assim, os macacos eram "felizes como ervas" (p. 127); o camelo, corcunda, "em trapos" (p. 128), "com grandes cílios empoeirados [...] sobre olhos que se tinham dedicado à paciência de um artesanato interno" (p. 128); a girafa, "silencioso pássaro sem asas" (p. 126), "virgem de tranças recém-cortadas", "quase verde", que "mais era paisagem que um ente" (p. 126-127). Como entender essa presença forte e surpreendente, reafirmada pelo título "O búfalo"? Será que estamos diante de uma fábula, gênero clássico e didático em uma de suas vertentes, com seu desfecho moralizante, a famosa moral da história? Afinal a mulher do casaco marrom vai ao Zoológico para aprender. Sabemos que o modelo da fábula resiste através dos tempos, às vezes completamente transfigurado. Basta pensar no bestiário famoso de Jorge Luis Borges $^{14}$, nas venenosas fábulas de Augusto Monterroso ${ }^{15}$, ou no sofisticado 0 bestiário ou cortejo de Orfeu, de Guillaume Apollinaire ${ }^{16}$. Mas, mesmo aludindo à aprendizagem, acredito que "O búfalo" não seja uma fábula, nem bestiário, pois a trama se equilibra em seus próprios paradoxos que, estes sim, fazem parte da construção de vários dos textos de Clarice. Se existe um projeto didático de espelhamento nos animais, aqui falta o principal, isto é, a "lição de ética", pois a mulher do casaco marrom quer aprender, não “o bem", mas a odiar. Assim, o que podemos afirmar com certeza é que "O búfalo" é um conto, gênero que também alcançou uma liberdade quase sem limites, além de muitas discussões, a partir do início do século XX. Tal situação fez com que Mário de Andrade, um dos principais modernistas brasileiros, afirmasse um dia que conto é o que o autor chama de conto.

13 Por outro lado, como dito acima, o tema dos animais está presente em muitos textos de Lispector, o que faz o crítico Benedito Nunes ${ }^{17}$ observar que os bichos constituem "uma simbologia do Ser", são símbolos palpáveis e sensíveis de uma "realidade primordial", ou de uma outra realidade. A insistência do tema também é clara em Laços de familia, às vezes como marca de estilo, ou esforço descritivo de personagens difíceis, como a adolescente, que desperta "como uma avestruz lenta se abre"18 em "Preciosidade". Mas essa insistência geralmente surge nos momentos de crise dos personagens, marcando tentativas vãs de solução. Assim acontece em "Uma galinha", salva num instante sentimental, até que um dia "mataram-na, comeram-se e passaram-se muitos anos"19. Também acontece com Ana em “Amor", pois além da visão do homem cego, que denuncia à protagonista sua própria "cegueira" na vida, as plantas e bichos do Jardim Botânico também a ajudam a problematizar a própria rigidez, atraindo-a "como um lobisomem é chamado pelo luar"20; e se ela, ao dormir, sopra "a pequena flama do dia" (p. 29), nada nos assegura que no futuro estará a salvo da paixão de viver, que não admite limitações. Por sua vez, Laura, em "A imitação da rosa", só consegue se libertar da mesmice da vida diária por meio da loucura e, internada, se sente "uma galinha indefesa no abismo da insulina" ${ }^{21}$.

Nos três últimos contos do livro os animais estão no centro do relato, de modo direto ou transfigurado. Assim acontece com os dois personagens fantasiados de galo e touro em 
"Mistério em São Cristóvão", outro texto com suspensão de sentido; em seguida acompanhamos as curiosas elucubrações a respeito do sepultamento de dois cães mortos, em "O crime do professor de matemática". "Mistério em São Cristóvão", magnificamente realizado, é o que mais se aproxima da ambiguidade de compreensão de "O búfalo", sem fornecer ao leitor nenhuma chave. Lemos e relemos e sempre nos perguntamos: mas o que realmente aconteceu?

Num texto de 1969, incluído em A descoberta do mundo, Clarice comenta o último conto de Laços de família, também desamarrando os laços e substituindo agentes, como se estivesse dentro do texto, escrevendo-o ainda:

[...] "O búfalo" me lembra muito vagamente um rosto que vi numa mulher ou em várias, ou em homens; e uma das mil visitas que fiz a jardins zoológicos. Nessa, um tigre olhou para mim, eu olhei para ele, ele sustentou o olhar, eu não, e vim embora até hoje. $\mathrm{O}$ conto nada tem a ver com isso, foi escrito e deixado de lado. Um dia relio e senti um choque de mal-estar e horror ${ }^{22}$.

No entanto, a cena descrita em "O búfalo" é em parte a mesma, se trocarmos "tigre" por "búfalo". A mulher do casaco marrom também não sustentou o olhar até o final, porque teve uma vertigem e desmaiou, enquanto o búfalo, "tranquilo de ódio, a olhava". Se a partilha era o ódio, como a narrativa veio repetindo, o ódio é a outra face do amor, ambos se completam. "Onde aprender a odiar para não morrer de amor?" "Eu te amo, disse ela então com ódio para o homem [...]." "Eu te odeio, disse, implorando amor ao búfalo."

Com alguma liberdade talvez percebamos que o jogo de afastamento e aproximação do búfalo e da mulher se assemelha ao que foi narrado pela autora em "A mudez cantada, a mudez dançada" ${ }^{23}$, na descrição do par de dançarinos do flamenco, dança cigana da Andaluzia. Nela encontramos "a conquista difícil", pois a rivalidade entre homem e mulher se põe a nu: "tão declarada é a guerra que não importam os ardís". A dançarina reconhece a coragem de seu par: "finalmente encontrou seu companheiro e inimigo. Os dois recuam eriçados. Reconheceram-se". E pode acontecer a morte "quando vier a paixão do ciúme". Eles se vingarão e estarão para sempre sozinhos, "porque só esta mulher era a sua inimiga, só este homem era o seu inimigo, e eles se tinham escolhido para a dança". Não é verdade que esta descrição da dança corresponde a um certo sentido paradoxal de "O búfalo"?

Quanto à protagonista do conto, a referência mais repetida é que ela usa um casaco marrom, às vezes com os punhos fechados dentro dos bolsos, numa atitude de ataque ou resistência. Existem outras referências em outros livros, mas em Laços de família o marrom é uma cor adequada a uma mulher pacata, vivendo o lugar estabelecido, na época, para as mulheres na sociedade e no casamento ${ }^{24}$. Laura, de "A imitação da rosa" por exemplo, se vê ao espelho com olhos marrons, cabelos marrons, sai com o marido trajando um vestido marrom, com seu "ar modesto de mulher"25. Ela era "castanha, como obscuramente achava que uma esposa devia ser" ${ }^{26}$. Tal mediocridade só é quebrada pela loucura que a transforma em "super-humana ${ }^{27}$ ", num "isolamento brilhante" ${ }^{28}$, entretanto ligado a seu desajuste mental.

19 A mulher do casaco marrom, já observamos, também possui um ponto de desequilíbrio, anunciado por "uma coisa branca" que se espalhava dentro dela; por sua vez a mesma sensação é interpretada por Laura de "A imitação da rosa" como "aquela coisa que um dia se alastrava clara, como um câncer, a sua alma". Sendo alguém que se debate, a mulher em "O búfalo" parece longe da cor castanha, mas a narradora a veste, não 
totalmente, mas com um casaco marrom. Por que será? Talvez para dizer que ela se debate, mas carrega em parte a sujeição feminina? Isto significa que não houve realmente uma saída para a situação da mulher. Sua educação religiosa, as lembranças devastadoras que a assaltaram na montanha-russa a respeito de sua sensualidade ${ }^{29}$, o ter sido difamada, além de recusada pelo amante, tudo isso cria seu sentimento de culpa e, ao mesmo tempo, tudo isso é alimento para seu desejo de ódio, empurrando-a para a esfera do imaginário, onde amor e ódio, o homem e o búfalo são um só ${ }^{30}$. A longa cena amorosa com o animal, olhos nos olhos, numa espécie de dança aderente de avanços e recuos, de vertigem erótica em câmera lenta, muito lenta, sugere um ato sexual terminado em "lenta vertigem", numa petite mort pós-coito, a distensão do gozo.

Relembramos que na construção de personagens em situações de conflito "O búfalo" se aproxima das outras narrativas irmanadas em Laços de família, com o acréscimo - e dificuldades para a análise - de que o conto parece construir-se, repito, segundo os procedimentos do sonho ou delírio, a despeito do esforço da narradora de apresentar detalhes explicativos : dizer, por exemplo, que a mulher do casaco marrom estava fraca, que não comia havia três dias, que sentia náuseas, parece uma tentativa de justificar a "coisa branca" que se espalhava dentro dela, "branca como papel, fraca como papel, intensa como uma brancura" (p. 133). Em suma, a "palidez tão funda" (p. 35) que foi trocada entre a mulher e o búfalo só pode ser entendida se associarmos o conto a "A imitação da rosa". É justamente a ideia de "imitação" a chave para o entendimento dos dois contos. Comecemos por reler os pensamentos de Laura:

Quando lhe haviam dado para ler a Imitação de Cristo ${ }^{31}$, com um ardor de burra ela lera sem entender mas, que Deus a perdoasse, ela sentira que quem imitasse Cristo estaria perdido - perdido na luz, mas perigosamente perdido. Cristo era a pior tentaçãa ${ }^{32}$.

21 Em seguida, mudando de registro, devemos reler algumas cartas trocadas entre Clarice e Fernando Sabino em 1946. Em uma delas Clarice comenta sua dificuldade na leitura da Imitação de Cristo, porque quem imitasse Cristo "estaria perdido" e "eu sou dos muitos chamados e não escolhidos..." ${ }^{33}$. Sabemos que grande parte dos amigos da escritora eram católicos, inclusive Fernando Sabino, e certamente essa leitura era inspirada por eles. Mas ao que tudo indica, o livro que perturbava Clarice não funcionou do mesmo modo para Laura, cuja solução irresistível de imitar a rosa leva-a à loucura, nem talvez para a mulher do casaco marrom que se entrega imaginariamente ao búfalo, imitação do homem que a desprezara, mas que a odeia e que a ama, afirmativa que não deixa de repetir a frase da carta, de estar entre os que foram chamados, mas não escolhidos. Quando a "palidez tão funda" (p. 135) foi trocada entre ambos, ela vai se tornando "dormente" (p. 135) até adormecer profundamente, embora de pé. Está em paz após tanto sofrimento, está inocente, ingênua, não quer, nem pode fugir "presa ao mútuo assassinato" (p. 135). Isto significa que ela também se mata, "como se sua mão se tivesse grudado para sempre ao punhal que ela mesma cravara" (p. 135)? Finalmente ela cai "enfeitiçada" numa vertigem lenta. Sua última visão foi "o céu inteiro e um búfalo" (p. 135). Se tudo isso faz parte de um delírio, como parece, ela está em paz.

Sabemos que as palavras "fantasia", "realidade", "verdade" estarão sempre entre aspas para respeitarmos o estatuto da ficção, apesar de "O búfalo" mostrar essas mesmas palavras tecidas com a mesma intensidade do coração da mulher do casaco marrom, coração que bate, não no peito, mas "entre o estômago e os intestinos" (p. 133). É neste conto que a proporção dos processos ficcionais se radicaliza em relação aos outros contos de Laços de família. A dificuldade de interpretá-lo está nesta radicalização. 
Saudando Perto do coração selvagem em 1943, Antonio Candido ${ }^{34}$ acertou ao afirmar que aquele romance era o primeiro, depois do modernismo de 1922, a explorar a linguagem literária, valendo esta tanto quanto o enredo. Tratava-se de um "romance de aproximação" com seu "ritmo de procura", tentando atingir o inalcançável ou o incompreensível. Penso que a posição que o conto ocupa no final de Laços de familia vale como se fosse o auge do requinte em relação ao tema dessa perda ou fracasso, tão explorado pela escritora em vários de seus livros.

Na primeira versão deste comentário, eu terminava dizendo que o leitor era livre para interpretar o desfecho como quisesse, sabendo que qualquer escolha seria precária. Achava que o melhor seria pensar no conto em suas várias interconexões, inclusive nos avanços e recuos entre texto e contexto (lugar da mulher naquela sociedade, por exemplo, ou as aporias da fé religiosa), desde que não se exigisse que tais procedimentos fossem como as ligações lógicas de um tratado sistemático. E, claro, sem esquecer que não existem respostas definitivas.

Lembrei então do último capítulo de Seis passeios pelos bosques da ficçãa ${ }^{35}$, de Umberto Eco, quando ele se pergunta: "por que não tentar criar mundos ficcionais tão complexos, contraditórios e provocantes quanto o mundo real"? Em suma, por que desconfiar de obras que se esforçam para ser tão ambíguas quanto a vida? Afinal os grandes autores fazem isto.

6 Acho que esta é uma conclusão justa para uma análise descritiva de "O búfalo", de Clarice Lispector.

\section{BIBLIOGRAFIA}

Pedro BLOCH, Entrevista - Vida, pensamento e obra de grandes vultos da cultura brasileira, Rio de Janeiro, Bloch Editores, s./d.

Antonio CANDIDO, "Uma tentativa de renovação", Antonio CANDIDO, Brigada ligeira e outros escritos, São Paulo, Livraria Martins Editora, 1945.

Roberto CORRÊA DOS SANTOS, Lendo Clarice Lispector, São Paulo, Atual, 1986.

Umberto ECO, Seis passeios pelos bosques da ficção, trad. Hildegard Feist, $3^{3}$ ed., São Paulo, Companhia das Letras, 1999.

Clarice LISPECTOR, Alguns contos, Rio de Janeiro, MEC (Ministério de Educação e Cultura), 1952.

Clarice LISPECTOR, Laços de familia, Rio de Janeiro, Francisco Alves, 1960.

Clarice LISPECTOR, Laços de família, Rio de Janeiro, Rocco, 2009.

Clarice LISPECTOR, "Fundo de Gaveta", em A legião estrangeira, Rio de Janeiro, Editora do Autor, 1964.

Clarice LISPECTOR, A descoberta do mundo, Rio de Janeiro, Nova Fronteira, 1984.

Benedito NUNES, O drama da linguagem - uma leitura de Clarice Lispector, São Paulo, Ática, 1989. 
Evelyn RocHA (org.), Encontros/Clarice Lispector, Rio de Janeiro, Azougue Editorial, 2011.

Fernando SABINO e Clarice LISPECTOR, Cartas perto do coração, Rio de Janeiro, São Paulo, Record, 2001.

Berta WALDMAN e Vilma ARÊAS (org.), Remate de Males, Revista do Departamento de Teoria Literária, no 9, Campinas, IEL/Unicamp, 1989.

\section{NOTAS}

1. Clarice LISPECTOR, entrevista publicada na revista Crisis, $\mathrm{n}^{\circ}$ 39, (julho de 1976) e republicada em Evelyn RochA (org.), Encontros/Clarice Lispector, Rio de Janeiro, Azougue Editorial, 2011, p. 121.

2. Clarice LISPECTOR, "O Búfalo", Laços de família, Rio de Janeiro, Rocco, 2009 [1960]. A partir de agora, as citações deste conto serão identificadas apenas com o número da página no próprio texto.

3. Clarice LisPeCtor, Alguns contos, Rio de Janeiro, MEC (Ministério de Educação e Cultura), 1952.

4. Alexandre EULÁLIO, "No Rio com Clarice", Boletim Bibliográfico LBL, Lisboa, 1961, republicado em Berta WALDMAN e Vilma ARÊAS (org.), Remate de Males, Revista do Departamento de Teoria Literária, no 9, Campinas, IEL/Unicamp, 1989.

5. No conto "Amor", do mesmo livro, a observação de um cego instala a crise da protagonista, que também reflete sobre a piedade. Cf. entre outras passagens: "Ah, era mais fácil ser um santo do que uma pessoa! Por Deus, pois não fora verdadeira a piedade que sondara em seu coração as águas mais profundas? Mas era uma piedade de leão" (p. 39).

6. "Cova" tem pelo menos dois sentidos: abertura na terra para enterrar um morto, sepultura, e toca de feras, covil.

7. Benedito Nunes aponta, como traço comum às personagens claricianas, "a violência represada dos sentimentos primários e destrutivos - cólera, ira, raiva, ódio - que subitamente explodem”. Benedito NUNES, O drama da linguagem - uma leitura de Clarice Lispector, São Paulo, Ática, 1989, p. 102.

8. Em análise minuciosa de "A imitação da rosa", conto do mesmo livro, Roberto Corrêa dos Santos observa que "a narrativa se realiza através de uma falsa terceira pessoa, simulacro da primeira [...] o que estabelece um duplo olhar, que é articulado à própria divisão íntima da protagonista". Roberto CORRÊA DOS SANTOS, Lendo Clarice Lispector, São Paulo, Atual, 1986.

9. Clarice LISPECTOR, A descoberta do mundo, Rio de Janeiro, Nova Fronteira, 1984, p. 494.

10. Ibid., p. 365.

11. Pedro BLOCH, Entrevista - Vida, pensamento e obra de grandes vultos da cultura brasileira, Rio de Janeiro, Bloch Editores, s./d., p. 7-11. As entrevistas são datadas de 1963, 1964 e 1965, a de Clarice é de 1964.

12. Evelyn RochA, op. cit., p. 88 e seguintes.

13. Ziraldo é um famoso cartunista e escritor brasileiro, um dos fundadores do Pasquim nos anos 1970, publicação de resistência à ditadura brasileira de 1964, escandalosamente radicalizada em 1968.

14. Jorge Luis BORGES e Margarita GUERRERO, O livro dos seres imaginários, Carmem Vera C. Lima (trad.), Porto Alegre, Rio de Janeiro, Globo, 1981. Cf. também: Alexandre EULÁLIO, "O bestiário famoso de Jorge Luis Borges", Carlos Augusto CALIL (org. e notas), Os brilhos todos, São Paulo, Companhia das Letras, 2017.

15. Augusto MONTERRoso, A ovelha negra e demais fábulas, Millôr Fernandes (trad.), São Paulo, Cosac Naify, 2014. É um livro de 1969 e a primeira edição brasileira é da Record, em 1983.

16. A primeira edição de Le Bestiaire ou Cortège d'Orphée é de 1911. A tradução e apresentação brasileira é de Álvaro Faleiros, São Paulo, Iluminuras, 1997. 
17. Benedito NUNES, O dorso do tigre, São Paulo, Perspectiva, 1969, p. 125.

18. Clarice LISPECTOR, Laços de família, op. cit., p. 87.

19. Ibid., p. 33.

20. Ibid., p. 20.

21. Ibid., p. 40.

22. Clarice LISPECTOR, A descoberta do mundo, p. 366. "Vim embora até hoje" é uma expressão coloquial que significa: "não me esqueço desse momento" ou "até hoje me lembro do que aconteceu", "o que fiz permanece até hoje".

23. Clarice LISPECTOR, "Fundo de Gaveta", A legião estrangeira, Rio de Janeiro, Editora do Autor, 1964, p. 236.

24. Cf. Roberto CORRÊA DOS SANTOS, "Leitura do conto 'A imitação da rosa", Lendo Clarice Lispector, p. 15 e seguintes.

25. Clarice LISPECTOR, Laços de família, op. cit., p. 35. Roberto Corrêa dos Santos também chama a atenção para o detalhe da cor marrom, opondo-a à luz. Cf. Roberto CORRÊA DOS SANTOS, op. cit., p. 24.

26. Clarice LISPECTOR, Laços de família, op. cit., p. 36.

27. Ibid., p. 38.

28. Id.

29. A mulher do casaco marrom se excita até com o calor que sente junto às jaulas: “[...] procurou a tepidez impura, o prazer percorreu suas costas até o mal-estar [...]” (p. 128).

30. Uma análise psicanalítica caberia neste conto, mas está fora de meu propósito.

31. Considerado por alguns o quinto livro dos Evangelhos, a obra foi escrita por Tomás de Kempis, nascido em 1380; Frei Tomás Borgmeier (trad.), Petrópolis, Editora Vozes, 2004, 34ª . ed.

32. Clarice LISPECTOR, Laços de família, op. cit., p. 36.

33. Fernando SABINo e Clarice LISPECTOR, Cartas perto do coração, Rio de Janeiro, São Paulo, Record, 2001, p. 54.

34. Antonio CANDIDO, "Uma tentativa de renovação", Brigada ligeira e outros escritos, São Paulo, Livraria Martins Editora, 1945. Primeiro livro editado pelo crítico, era uma recolha de várias publicações na imprensa. O artigo sobre Clarice foi o rodapé da Folha da Manhã, em 1943. Mais tarde o artigo ganhou o título de "No raiar de Clarice Lispector".

35. Umberto ECO, Seis passeios pelos bosques da ficção, Hildegard Feist (trad.), $3^{\mathrm{a}}$ ed., São Paulo, Companhia das Letras, 1999, p. 123.

\section{RESUMOS}

Cette analyse de «O Búfalo », un conte de Clarice Lispector, est basée sur trois procédés : (a) la description du texte, (b) l'analyse des aspects constructifs des événements narrés et (c) l'interprétation finale. Bien que Clarice fût une écrivaine expérimentale, elle n'a jamais renoncé à revenir à certaines images, situations ou forces mouvantes de sa fiction. Le paradoxe constitue ainsi une espèce de pierre fondamentale de « $O$ Búfalo ». C'est pourquoi nous mobilisons d'autres récits de l'écrivaine pour comparer l'emploi des paradoxes dans des situations plus ou moins proches dans le but d'intégrer le sens possible du conte.

This analysis of "O Búfalo", a short story by Clarice Lispector, is structured according to three procedures: (a) description of the text, (b) analysis of its plot and (c) final interpretation. 
Although being a real experimenter, Lispector always brings back some of the traces we find in all the books she wrote. An example: the plot of "The Buffalo" is supported by paradoxes, which makes conclusions uncommon; so the analysis also examines paradoxes in different works by her, to compare their function and so reach a more conclusive argument concerning the meaning of this short story.

\section{ÍNDICE}

Mots-clés: Laços de família, o Búfalo, description, analyse, interprétation, forces mouvantes, paradoxe, intégration

Keywords: Laços de família, o Búfalo, description, analysis, interpretation, traces, paradox, final conclusion

\section{AUTOR}

\section{VILMA ARÊAS}

Universidade Estadual de Campinas - UNICAMP 